\title{
Capitalismo Brasileiro e Responsabilidade Social Empresarial $^{1}$
}

\author{
Brazilian Capitalism and Corporate Social Responsibility
}

\section{Leandro Martins Zanitelli}

\begin{abstract}
Resumo: Este artigo se dedica a levantar hipóteses sobre a responsabilidade social empresarial no Brasil. Para tanto, vale-se de duas vertentes distintas da literatura sobre comportamento das empresas, uma que procura definir os fatores, não apenas estratégicos, mas também institucionais, da responsabilidade social empresarial, e outra, conhecida como abordagem das "variedades de capitalismo", que se empenha em descrever o impacto das diferentes instituições (normas e práticas) características do capitalismo de cada país sobre a atuação das empresas. Foram elaboradas, como resultado, seis hipóteses sobre a conduta socialmente responsável das empresas no Brasil.
\end{abstract}

Palavras-chave: Responsabilidade Social Empresarial. Brasil. Variedades de Capitalismo.

\begin{abstract}
The paper raises hypotheses regarding corporate social responsibility in Brazil. It draws on two distinct branches of the literature concerning the behavior of firms, one that seeks to determine both the strategic and institutional factors conditioning firms' social performance and other, known as the "varieties of capitalism" approach, describing the impact of different institutions (norms and practices) featured by national capitalisms on firms' strategies. As a result, six hypotheses about the social performance of enterprises in Brasil are formulated.
\end{abstract}

Keywords: Corporate Social Responsibility. Brazil. Varieties of Capitalism.

\section{Introdução}

Há diversas razões pelas quais a responsabilidade social empresarial interessa ao Direito e, em especial, à Política do Direito. Em primeiro lugar, a responsabilidade social da empresa pode ser concebida como

\footnotetext{
${ }^{1}$ Recebido em: 12/07/2012.

Revisado em: 15/10/2012.

Aprovado em: 16/10/2012.
} 
obediência às normas jurídicas, de modo que, quanto maior a responsabilidade social, maior é a eficácia das disposições legais. Em segundo lugar, a responsabilidade social empresarial, entendida como obediência à lei, pode ser também o objetivo da regulação jurídica. Em outras palavras, o Direito pode ser visto como meio de prescrever às empresas certos comportamentos, e também de lograr que esses comportamentos de fato se verifiquem. A afirmação pode soar trivial, mas tem que ser entendida em um contexto no qual é comum constatar as dificuldades dos meios de regulação tradicional (a regulação de "comando e controle") e da forma jurídica que lhe corresponde, a norma estatal sancionadora. Em tal contexto importa cada vez mais não apenas o conteúdo da regulação jurídica, mas o papel a ser exercido por essa regulação em uma estratégia global de governança que tem no Direito apenas um dos seus possíveis instrumentos (LOBEL, 2004; TRUBEK; TRUBEK, 2006). Em terceiro lugar, a responsabilidade social empresarial também é merecedora de atenção quando consiste em práticas que excedem o exigido pela legislação. Mesmo que em um caso assim a atuação socialmente valiosa da empresa não corresponda, por definição, ao cumprimento de um dever jurídico, tal atuação é importante porque revela a dispensabilidade, e quem sabe até a indesejabilidade, da intervenção jurídica. É recomendável, pois, determinar em que áreas, ou sob quais circunstâncias, as empresas se conduzem ou estão mais propensas a se conduzir de maneira socialmente responsável, para então voltar esforços aos casos em que a lei se faça de fato necessária e não corra o risco de inibir um comportamento que seria capaz de se verificar independentemente dela. ${ }^{2}$ Por fim, o comportamento socialmente responsável (ou a falta desse comportamento) da empresa é relevante pela influência que exerce sobre o conteúdo do Direito, seja no processo legislativo, isto é, por ocasião da criação das normas jurídicas, seja na aplicação destas últimas. ${ }^{3}$

\footnotetext{
2 O último ponto tem a ver com o efeito perverso dos incentivos (dos quais a sanção legal é exemplo proeminente). Para um sumário da literatura a esse respeito, ver Gneezy, Meier e Rey-Biel (2011).

3 Sobre a influência dos sujeitos regulados na definição do sentido de normas instituídas, ver Edelman, Uggen e Erlanger (1999).
} 
A hipótese central deste trabalho é a de que o comportamento empresarial, e, por conseguinte, o comportamento socialmente responsável da empresa, varie de acordo com a espécie de capitalismo sob a qual a empresa atue. A fim de esmiuçar tal hipótese, tomam-se como base estudos de Economia Política comparada, especialmente os inspirados pela abordagem conhecida como "variedades de capitalismo" (HALL; SOSKICE, 2001). Embora a literatura sobre as variedades de capitalismo tenha de início se limitado a países como EUA, Reino Unido e Alemanha, mais recentemente tem havido tentativas de incluir na comparação nações mais pobres ou menos industrializadas, entre elas as da América Latina (SCHNEIDER, 2009; SÁNCHEZ-ANCOCHEA, 2009; SCHNEIDER; KARCHER, 2010) e, em particular, o Brasil. (NÖLKE, 2010)

A ideia de estudar a responsabilidade social empresarial a partir da comparação entre capitalismos não está sendo apresentada aqui pela primeira vez (MATTEN; MOON, 2008; GJØLBERG, 2009; JACKSON; APOSTOLAKOU, 2010). Em geral, no entanto, a literatura se restringe a comparar práticas de responsabilidade social corporativa em países da Europa ocidental e nos EUA, tendo em vista, assim, apenas as duas variedades de capitalismo distinguidas por Hall e Soskice (2001), o capitalismo das "economias de mercado liberal" (sigla em inglês, LMEs), de que são exemplos os EUA e o Reino Unido, e o das "economias de mercado com coordenação" (sigla em inglês, CMEs), de que são exemplos a Alemanha e o Japão. Ficam de fora, assim, os países cuja situação difira significativamente da desses dois tipos, como parece ser o caso do Brasil e dos demais países da América Latina. ${ }^{4}$ No que se refere, por outro lado, à literatura que examina o caso brasileiro à luz das variedades de capitalismo, os trabalhos têm-se cingido às características gerais do capitalismo brasileiro e, em especial, a apresentar o Brasil como país pertencente a

\footnotetext{
4 Vários trabalhos atentam para a atuação além-fronteiras de empresas com origem em países de LME e CME (AMAESHI; AMAO, 2009; GJØLBERG, 2009; JACKSON; APOSTOLAKOU, 2010). No entanto, mesmo que esses trabalhos abarquem, como consequência, as práticas de responsabilidade social dessas empresas nos países hospedeiros, o que eles têm em vista é a influência das instituições do país de origem, e não das instituições locais, sobre o comportamento empresarial e, em particular, a diferença de comportamento de empresas provenientes de LMEs e CMEs.
} 
um tertium genus em relação às CMEs e às LMEs (SCHNEIDER, 2009; NÖLKE, 2010) ou à análise de outras variáveis que não a responsabilidade social empresarial, como a inovação tecnológica (DELGADO; CONDÉ; ÉSTHER, 2010) e o treinamento de trabalhadores. (BALESTRO; MARINHO; WALTER, 2001)

O presente artigo procura suprir, pois, a falta de estudos sobre as particularidades do capitalismo brasileiro e sua relação com a responsabilidade social empresarial. Para tanto, é dividido em mais quatro seções além desta seção introdutória. Na seção II, trata-se mais detalhadamente do conceito de responsabilidade social empresarial e dos fatores que levam as empresas a atuar de maneira socialmente responsável. Na seção III, descrevem-se, inicialmente, as características gerais da abordagem das variedades de capitalismo, para em seguida passar à aplicação dessa abordagem ao caso brasileiro. A seção IV levanta hipóteses sobre as implicações das peculiaridades da variedade de capitalismo brasileira para a responsabilidade social empresarial, como a quinta e última seção chama a atenção para alguns limites do trabalho e encerra com considerações sobre a regulação da atividade empresarial e sugestões para a pesquisa futura.

\section{Responsabilidade Social Empresarial}

Um inconveniente costumeiramente reconhecido da pesquisa em torno da responsabilidade social empresarial é a variedade de sentidos que são atribuídos a essa expressão (GARRIGA; MELÉ, 2004). Essa variedade talvez seja, contudo, inevitável, dada a diversidade dos objetivos de pesquisa e até das áreas do conhecimento em que a responsabilidade social da empresa é tratada. É indispensável esclarecer, pois, em qual das suas muitas acepções a expressão usada aqui.

Uma primeira definição crucial é sobre se a responsabilidade social da empresa constitui atividade em conformidade com os ditames legais, além do que prescrevem esses ditames, ou ambos. Como já sugerido na seção introdutória, a escolha deste trabalho é pela terceira das alternativas, isto é, por designar como responsabilidade social da empresa tanto a atividade de cumprimento das determinações legais como a que vai além 
desse cumprimento. Convém ressaltar, porém, algumas dificuldades que essa escolha traz consigo.

Uma delas consiste em determinar que modos de atuação, entre aqueles não legalmente prescritos, são modos de atuação socialmente responsáveis. Considerar-se-á aqui como tais aqueles comportamentos que se prestem à realização dos direitos humanos, à preservação do meio ambiente e à salvaguarda dos interesses de certos grupos que não os sócios ou acionistas (como, por exemplo, trabalhadores e consumidores) ainda que, ao menos a curto prazo, isso contrarie o objetivo de maximização do lucro. Note-se, porém, que essa definição é imprecisa, por no mínimo três razões: a) porque se vale de direitos (os direitos humanos) cujo conteúdo é em larga medida controvertido; b) porque não enumera todos os interessados, ou stakeholders, que a atividade empresarial socialmente responsável tem em vista; e c) porque não estipula como eventuais colisões de bens (por exemplo, entre a proteção do meio ambiente e o interesse dos consumidores) hão de ser resolvidas.

Uma segunda dificuldade diz respeito ao fato, mencionado no parágrafo antecedente, de o comportamento empresarial aqui dito socialmente responsável poder não apenas exceder o que é legalmente exigido, como fazê-lo de maneira que contrarie os interesses dos acionistas. Diante disso, é de indagar se a atuação socialmente responsável da empresa não acaba ocasionalmente violando direitos de propriedade, isto é, se a decisão do administrador pela responsabilidade social além do legalmente exigido não caracteriza o descumprimento de um dever que esse administrador possua para com os titulares das ações ou cotas do capital social. Assim, uma vez aceita a definição já proposta, seria importante estabelecer em que casos o atendimento de interesses outros que não os dos sócios, embora não legalmente prescrito, pode ainda se considerar lícito. ${ }^{5}$

\footnotetext{
5 Que a legislação brasileira obrigue os controladores e administradores de sociedades por ações a ter em conta os interesses de outros stakeholders é algo que decorre, sem dúvida, do que prescrevem os artigos 116, parágrafo único (segundo o qual o acionista controlador deve fazer com que a companhia cumpra a sua "função social", possuindo "deveres e responsabilidades para com os demais acionistas da empresa, os que nela trabalham e para com a comunidade em que atua") e 154, caput ("o administrador deve exercer as atribuições que a lei e o estatuto lhe conferem para lograr os fins e no interesse
} 
Feitas essas observações, passa-se a considerar o que leva uma empresa a atuar de maneira socialmente responsável, tratando-se tal atuação, como dito, como uma que obedece e também excede, por vezes, o que é legalmente exigido. Para tanto, far-se-á a distinção entre fatores estratégicos e institucionais da responsabilidade social empresarial.

Fatores estratégicos da responsabilidade social são os que põem essa responsabilidade a serviço do sucesso da empresa, a curto ou longo prazo. Boa parte da pesquisa acerca da responsabilidade social da empresa diz respeito a esses fatores, já que trata da relação entre responsabilidade social e "desempenho financeiro" (financial performance). ${ }^{6}$ Não é possível enumerar aqui todas as razões aventadas para que a atuação socialmente responsável da empresa contribua para o aumento do seu valor. ${ }^{7}$ Entre essas razões estão, por exemplo, a preferência de consumidores (DU; BATTACHARYA; SEM, 2007; MOHR; WEBB, 2005), trabalhadores (GREENING; TURBAN, 2000) e investidores (O'ROURKE, 2003; JOHNSON; GREENING, 1999; GRAVES; WADDOCK, 1994) por firmas socialmente responsáveis, bem como o aumento de produtividade obtido com a melhora das condições de trabalho (COLQUITT; CONLON; WESSON, 2001). Quando se inclui a observância à lei entre os modos de atuação socialmente responsáveis, pode-se considerar também como um fator estratégico as diferentes sanções aplicáveis ao descumprimento, como multas, suspensão de atividade e negativa de acesso a crédito público.

Além de fatores estratégicos, a responsabilidade social empresarial pode ainda ser determinada por fatores institucionais. O uso do vocábulo

da companhia, satisfeitas as exigências do bem público e da função social da empresa"). O que essas disposições não deixam claro é em que medida o cumprimento da função social da empresa permite (se é que permite) ao acionista controlador e ao administrador preterir os interesses dos demais acionistas em benefício de terceiros.

6 Para uma síntese da literatura a esse respeito e meta-análise dos resultados de estudos empíricos que indica uma correlação positiva entre desempenho social e financeiro, ver Orlitzky, Schmidt e Rynes (2003).

7 Assim como se supõe que a responsabilidade social ocasionalmente favoreça o bom desempenho financeiro, cogita-se também do contrário, isto é, que o sucesso da empresa leve ao incremento da responsabilidade social. (WADDOCK; GRAVES, 1997) 
“instituição" está atrelado à sociologia das organizações e, em particular, à sua vertente institucionalista (MEYER; ROWAN, 1977; DiMAGGIO; POWELL, 1983); para um sumário, ver Scott (2008), que mais recentemente tem inspirado estudos sobre as causas da responsabilidade social empresarial (CAMPBELL, 2007; 2006; AGUILERA; RUPP; WILLIAMS, 2007). "Instituições" são, no sentido dessa tradição de pesquisa, normas e quadros cognitivos a partir e nos limites dos quais a ação tem lugar. No que se refere, em especial, às organizações, o sentido da teoria institucional não é o de negar importância ao comportamento estratégico, mas o de afirmar, em síntese, que a atuação das organizações é por vezes mais acuradamente descrita como a de uma pura e simples conformidade a certos padrões (legais, sociais, profisssionais, etc.), seja em razão da internalização desses padrões (por exemplo, as normas de conduta profissional instiladas em escolas de Administração), das expectativas de outrem (por exemplo, colegas, consumidores e trabalhadores) ou até da incapacidade para conceber conduta diversa (o taken-for-grantedness, ou insuscetibilidade à crítica, de determinadas condutas).

A diferença entre os pontos de vista, exclusivamente estratégicos e institucionalistas, é bem ilustrada pela análise de Suchman (1995) a respeito da legitimidade de organizações. De acordo com Suchman, o empenho de uma organização em legitimar-se (isto é, em ser percebida pelo público como apropriada e até mesmo desejável) pode, por um lado, ser encarado como indispensável ao sucesso dessa organização (abordagem estratégica). No entanto, é também possível, por outro lado, entender a busca pela legitimidade como imposição do conjunto de normas, símbolos e ritos que sobrepairam à vida organizacional (abordagem institucionalista). De acordo com esse último ponto de vista, a legitimidade é perseguida antes como fim em si mesma, efeito puro e simples de uma exigência de conformidade proveniente das circunstâncias e dos processos cognitivos que essas mesmas circunstâncias impõem ou facilitam, do que como meio para obter vantagem sobre organizações rivais.

Embora as duas perspectivas não sejam, como antes observado, excludentes, é importante notar como suas implicações divergem. Segundo a abordagem estratégica, seria de prever que a responsabilidade social empresarial somente se verifique se, e à medida que, contribua para 
o sucesso da organização. De acordo com a abordagem institucional, em contrapartida, um possível resultado da influência institucional é o comportamento disfuncional (MEYER; ROWAN, 1977), isto é, que não serve ao máximo aproveitamento dos recursos disponíveis. Essa última abordagem deixa antever, portanto, práticas de responsabilidade social que não se relacionem, a curto ou a longo prazo, com o sucesso da empresa.

Segundo Campbell (2007) $)^{8}$, entre os fatores institucionais da responsabilidade social corporativa estão: a) a criação e a aplicação de normas estatais, sobretudo quando essas normas forem estabelecidas à base de negociação e, quando possível, consenso de governo, empresas e outros atores relevantes (por exemplo, sindicatos e ONGs); b) a autorregulação empresarial, especialmente quando essa autorregulação for apoiada pelo Estado; c) atores privados, tais como ONGs, organizações de movimentos sociais, investidores institucionais e órgãos de imprensa, que observem o comportamento das empresas e se empenhem, quando preciso, para modificá-lo; d) adesão a normas de responsabilidade social pelo público em geral e pelas escolas, publicações especializadas e demais instâncias de formação de administradores; e) associações empresariais que promovam a responsabilidade social; f) diálogo "institucionalizado" entre empresas e sindicados, trabalhadores, a comunidade local, investidores e outros stakeholders. Seguem alguns comentários acerca de cada um dos fatores enumerados.

\footnotetext{
8 Tendo em vista a atenção dada nessa parte do texto à análise de Campbell (2007) sobre os antecedentes institucionais da responsabilidade social, é recomendável salientar um ponto de convergência e outro de divergência entre o sentido emprestado à responsabilidade social empresarial por esse autor e o sentido do presente trabalho. A convergência se deve ao fato de Campbell (2007, p. 950) ter em vista práticas de responsabilidade social, e não a mera declaração de adesão a princípios de responsabilidade social que termina por não se traduzir, muitas vezes, em uma mudança significativa de comportamento. $\mathrm{O}$ mesmo autor define, porém, como socialmente responsável a empresa que se abstém de fazer tudo aquilo que sabidamente possa causar dano a alguns de seus stakeholders (CAMPBELL, 2007, p. 951), o que leva a tratar os deveres de responsabilidade social da empresa como deveres eminentemente negativos (isto é, deveres de não causar dano). A ideia de responsabilidade social empresarial de que se vale este estudo difere da de Campbell quanto a isso, já que permite atribuir à empresa deveres positivos para além da mera reparação do dano. Para uma análise sobre o conteúdo (negativo ou positivo) dos deveres das empresas, ver Bilchitz (2010).
} 
a) Como observado anteriormente, a intervenção estatal transforma a responsabilidade social em comportamento estratégico, indispensável a que a empresa permaneça imune às sanções que as normas estatais estabelecem. Isso não impede, todavia, de tratar a regulação estatal como fator institucional da responsabilidade social, que favorece boas práticas empresariais à medida que o conteúdo das normas jurídicas (ou a obediência à lei pura e simples) seja internalizado (SUNSTEIN, 1996, p. 2.031-2.033) pelos administradores ou por outros atores (trabalhadores, consumidores, etc.) cujas expectativas os primeiros se sintam premidos a atender. Como para o comportamento estratégico o que importa é a gravidade da sanção cominada para o descumprimento de uma norma e a probabilidade de essa sanção ser de fato aplicada, para a visão institucionalista dessa responsabilidade, em contrapartida, consideram-se outros fatores de eficácia das normas jurídicas para além da sanção. Daí o porquê da possível preferência por uma legislação negociada, por exemplo, que se alinhe às evidências sobre a importância, para a obediência de uma norma, da percepção acerca da justeza do procedimento mediante o qual essa norma foi estabelecida. (TYLER, 1997)

b) Ainda que a autorregulação empresarial possa ter de início uma motivação estratégica (como, por exemplo, a de prevenir a regulação pelo Estado), a perspectiva institucionalista apela para que não se ignore o potencial da autorregulação para produzir alterações cognitivas e normativas ensejadoras da responsabilidade social empresarial (GUNNINGHAM; REES, 1997, p. 386-388). Uma cogitação, a esse respeito, é a de que normas autoimpostas tenham mais chances de ser obedecidas (OSTROM, 2000, p. 148). O apoio estatal à autorregulação é importante para fazer valer os códigos de conduta estabelecidos pelas empresas, evitando, assim, que tentativas de autorregulação sejam sabotadas pelo comportamento oportunista de algumas delas (CAMPBELL, 2007, p. 956; GUNNINGHAM; REES, 1997, p. 394). Entre empresas sujeitas à concorrência, qualquer medida de responsabilidade social que traga consigo aumento de custos depende da percepção de que não haverá oportunismo das firmas rivais, isto é, de que a empresa com atuação socialmente responsável não será a única a conduzir-se assim. 
c) A exemplo da legislação, a atuação de sujeitos não estatais pode tornar a responsabilidade social não apenas estrategicamente valiosa (isto é, valiosa como meio para o sucesso financeiro), como também contribuir para o desenvolvimento de um ambiente institucional propício a essa responsabilidade. Os referidos sujeitos exercem um papel coercivo (DiMAGGIO; POWELL, 1983, p. 150) não só pela "pressão informal" que diretamente realizam sobre as empresas mas também pela sua atuação como "empreendedores de normas" (SUNSTEIN, 1996, p. 2.030-2.031) que influem sobre as expectativas do público em relação ao comportamento empresarial.

d) Fatores em que a conduta empresarial pode se adequar a certas pautas ainda quando tal adequação se mostre disfuncional (isto é, contrária ao ótimo aproveitamento dos recursos disponíveis) são as normas inculcadas em seus administradores, particularmente (mas não só) no período de formação profisssional.

e) Associações comerciais podem exercer um papel educativo relevante para a responsabilidade social. A sugestão é a de que a participação em associações pode levar as empresas a aprenderem umas com as outras acerca dos benefícios a longo prazo da atuação socialmente responsável, algo que, embora de início atrelado instrumentalmente ao interesse das empresas mesmas (isto é, dos sócios), acaba ajudando a desenvolver um "ambiente normativo" favorável à responsabilidade social. (CAMPBELL, 2007, p. 959)

f) Postula-se que o diálogo entre empresários e grupos de interessados, como trabalhadores, consumidores e comunidades locais, sirva para aproximar pontos de vista e, quando incapaz de levar ao consenso, reduza, ao menos, o antagonismo entre as partes envolvidas. Campbell (2007, p. 960-961) chama a atenção, a esse respeito, para a importância de meios institucionais (legais, inclusive) que favoreçam o diálogo entre administradores de empresas e outros stakeholders, como as regras de participação dos trabalhadores na gestão encontradas na Alemanha e a regulação 
local da preservação ambiental com a participação de firmas, autoridades governamentais e representantes das comunidades nos EUA. ${ }^{9}$

\section{Variedades de Capitalismo: os casos da América Latina e do Brasil}

A diferença fundamental entre as duas variedades de capitalismo comparadas por Hall e Soskice (2001), a das "economias de mercado liberais" (LMEs) e a das "economias de mercado com coordenação" (CMEs) diz respeito ao modo como as empresas se relacionam umas com as outras, com trabalhadores e investidores (HALL; SOSKICE, 2001, p. 8). Nas LMEs, essas relações são predominantemente mediadas pelo mercado, isto é, pela oferta e procura de bens. Trata-se, em consequência, de relações pouco duradouras, baseadas muito mais em contratos feitos por escrito do que na interação de longa data. Nas CMEs, em contrapartida, relações de mercado são mais frequentemente substituídas pela interação duradoura entre firmas e outros atores. Essas interações, ou redes, exercem um papel crucial para a troca de informações, troca essa que, aliada ao interesse na continuidade das relações, acaba por se mostrar um poderoso meio de prevenir comportamentos desleais ou oportunistas.

Hall e Soskice (2001, p. 7) tratam das implicações dessa diferença fundamental entre as LMEs e as CMEs em cinco áreas de atuação das empresas: a) relações industriais; b) treinamento vocacional e educação; c) governança corporativa; d) relações entre firmas; e) relações entre a firma e seus empregados. A análise é feita a partir do contraste entre o capitalismo norte-americano, um exemplo de LME, e o capitalismo alemão, um exemplo de CME.

Nos EUA, a falta de interação das empresas entre si e com os sindicatos (relações industriais) previne a concertação a respeito dos salá-

9 A eficácia comportamental da comunicação face a face é atestada por estudos experimentais com jogos de bens públicos. Quando os participantes dos experimentos têm a chance de se comunicar previamente, o nível de contribuição para a causa comum aumenta, ainda mais quando essa comunicação acontece face a face. (OSTROM, 2000, p. 140-141; OSTROM; WALKER; GARDNER, 1992) 
rios pagos, o que deixa a relação da firma com seus empregados mais sensível às flutuações do mercado (HALL; SOSKICE, 2001, p. 29). No que se refere à relação com investidores (governança corporativa), o que predomina é a pulverização acionária e a consequente dificuldade para a constituição de relações duradouras e canais de informação, do que decorre uma maior sensibilidade dos investidores aos resultados publicados em balanço, muitas vezes a única fonte de informação disponível. O preço das ações é, portanto, facilmente influenciado pelos resultados, o que deixa as empresas mais expostas a aquisições (HALL; SOSKICE, 2001, p. 29). Quanto ao treinamento de trabalhadores, há mais investimento no desenvolvimento de habilidades gerais (úteis para o trabalho em mais de uma firma, e até em mais de um setor de atividade) do que específicas (HALL; SOSKICE, 2001, p. 30). A ênfase em habilidades gerais se explica pela instabilidade das relações de trabalho, corolário, por sua vez, não apenas do fato de tais relações serem regidas pelo mercado, como também da "impaciência" dos investidores, a qual leva as empresas a ter de reagir prontamente a eventuais mudanças de circunstâncias, muitas vezes mediante a despedida de trabalhadores. Por outro lado, a fragilidade das relações entre firmas acaba desencorajando a provisão de treinamento pelo empregador, que teme mais vivamente ter seus empregados atraídos por empresas concorrentes. Prevalece, também, por isso, o treinamento em habilidades gerais, obtido fora do ambiente de trabalho, principalmente em escolas e universidades. (HALL; SOSKICE, 2001, p. 30)

A importância das relações não mediadas pelo mercado no capitalismo alemão se faz notar, em primeiro lugar, na área da governança corporativa. Em contraste com LMEs, nas quais os resultados de balanço costumam ser a principal, senão única, fonte de informação a respeito da companhia, a atuação de grandes investidores, como bancos, enseja uma relação mais próxima, com maior fluxo de informações, entre investidores e administradores na Alemanha (HALL; SOSKICE, 2001, p. 23). A maior difusão de informações sobre a situação de cada firma é auxiliada pelas associações comerciais, que, a fim de promover a cooperação em áreas como treinamento de trabalhadores e transferência de tecnologia, forçam as empresas a compartilhar informações (HALL; SOSKICE, 2001, p. 23). A atuação das associações comerciais é decisiva para as re- 
lações industriais, levando ao alinhamento de salários e à consequente redução da competição por mão-de-obra (HALL; SOSKICE, 2001, p. 2425). Por essa razão e, também, devido à participação de representantes dos trabalhadores nos conselhos de gestão e a um investimento menos suscetível a oscilações, as relações de trabalho na Alemanha são muito mais estáveis do que nos EUA (HALL; SOSKICE, 2001, p. 25). A ênfase quanto à capacitação dos trabalhadores é no desenvolvimento de habilidades específicas da firma ou do setor de atividade, algo encorajado, por um lado, pela negociação coletiva dos salários e pelas redes empresariais cultivadas por meio das associações, que reduzem o risco de aliciamento de trabalhadores por empresas concorrentes e preservam, assim, o incentivo da firma a investir em treinamento, e, por outro, pela estabilidade no emprego, decisiva para o incentivo dos trabalhadores a investir no desenvolvimento de aptidões que não lhes serão úteis em outra empresa ou setor. (HALL; SOSKICE, 2001, p. 25)

Hall e Soskice (2001, p. 8) tratam as duas variedades de capitalismo examinadas como tipos ideais, "[...] pólos de um espectro ao longo do qual muitas nações se situam". A ideia, em outras palavras, é que a classificação proposta seja aplicável a muitos outros casos além dos mais exemplares (EUA e Reino Unido para LMEs, Alemanha e Japão para CMEs), os quais, de acordo com a maior ou menor importância das relações não mediadas pelo mercado, constituiriam economias mistas ou intermediárias, ora mais próximas de uma CME, ora de uma LME. Outros autores, ao revés, propõem distinguir mais variedades de capitalismo além das duas referidas. Esse é o caso de autores, como Schneider (2009), Nölke (2010) e Bresser-Pereira (2012), que procuram estender a abordagem das variedades de capitalismo para os países da América Latina e, em particular, o Brasil.

De acordo com Schneider (2009), o capitalismo nos países da América Latina aproxima-se de um terceiro tipo ideal, o das economias de mercado hierárquicas (sigla em inglês, HMEs). ${ }^{10}$ A exemplo das CMEs, as HMEs caracterizam-se pelo fato de parte considerável da atuação das

10 Ao todo, Schneider (2008) distingue quatro variedades de capitalismo, LMEs, CMEs, HMEs e NMEs (economias de mercado de redes, network market economies). 
firmas não ser mediada pelo mercado. Ao contrário, porém, das CMEs, nas quais as relações não baseadas em mercado se distinguem pela paridade, isto é, são relações de negociação (por exemplo, as relações entre firmas facilitadas pelas associações, ou entre investidores e administradores), essas mesmas relações são, nas HMEs, marcadas pela hierarquia. (SCHNEIDER, 2008)

$\mathrm{Na}$ América Latina, a substituição do mercado e de meios negociados de coordenação pela hierarquia verifica-se em diversas searas (SCHNEIDER, 2009). Nos grupos de empresas familiares, muito comuns, a baixa dispersão do capital eleva a subordinação dos administradores aos sócios, também frequentemente envolvidos, eles próprios, em relações de hierarquia oriundas da distribuição do capital, das relações familiares ou ambos (SCHNEIDER, 2009, p. 8). A hierarquia se faz presente também na governança das empresas subsidiárias de multinacionais, sujeitas, em maior ou menor medida, às determinações dos gestores da empresa holding (SCHNEIDER, 2009, p. 8-9). Muito embora a dependência do mercado acionário seja reduzida em relação às LMEs, faltam incentivos para o investimento paciente encontrado nas CMEs, já que a produção é ora de baixa tecnologia e mão-de-obra pouco capacitada (caso, geralmente, dos grupos familiares), ora de tecnologia facilmente transferível para outras localidades (caso das multinacionais) (SCHNEIDER, 2009, p. 15-16). Nas relações das empresas com seus fornecedores e clientes, fatores de hierarquização são a atuação de grandes empresas (grupos familiares ou multinacionais) e a frequente formação de oligopólios (SCHNEIDER, 2009, p. 8-9). Em contraste com as CMEs, nas quais um traço importante de coordenação não hierárquica corresponde à atuação das associações comerciais e à relação dessas associações com os sindicatos de trabalhadores, as associações comerciais têm papel pouco significativo nas HMEs, algo atribuível, no caso da América Latina, à diversificação da atividade dos grupos familiares, ao reduzido poder decisório dos administradores de empresas subsidiárias de multinacionais e até à pequena familiaridade desses últimos com os empresários locais (SCHNEIDER, 2009, p 15). Talvez devido à maciça intervenção estatal nas relações de trabalho, a negociação acerca dessas relações é geralmente mediada pelo Estado, outro ingrediente de hierarquia que se contrapõe ao modo mais 
paritário de concertação entre capital e trabalho observado em CMEs (SCHNEIDER, 2009, p. 19). Apesar da generosa legislação trabalhista, sindicatos de trabalhadores têm pouca força e, quando atuam, fazem-no antes nos gabinetes de governo do que no chão de fábrica, algo que, aliado à falta de incentivo ao investimento paciente e à baixa capacitação dos trabalhadores, torna as relações de trabalho instáveis e marcadamente hierárquicas. (SCHNEIDER, 2009, p. 10)

Nölke (2010) se vale do método comparativo das variedades de capitalismo para tratar dos países do grupo BRIC (Brasil, Rússia, Índia e China) e, em particular, do Brasil. Sua análise coincide, em vários pontos, com a que faz Schneider (2009) para a América Latina em geral, mas chama a atenção para algumas particularidades do caso brasileiro capazes de atenuar à índole hierárquica de certas relações empresariais, tal como o fato de as empresas multinacionais se sujeitarem a maior competição do que a verificada em outros países latino-americanos (NÖLKE, 2010, p. 7). Além disso, as empresas familiares, embora significativas, tiveram um decréscimo da sua participação no grupo das maiores empresas ao longo dos anos 1990, cedendo lugar para empresas de propriedade minoritária dominante (dominant minority property), cujos controladores dispõem de apenas 20 a 50\% do capital. (NÖLKE, 2010, p. 8)

A análise de Nölke (2010, p. 3) também salienta a substituição de relações mediadas pelo mercado pelas relações, formais e informais, entre empresas e Estado, o que o leva a designar a economia brasileira como uma economia de clãs, caracterizada por uma estreita cooperação entre empresas e agentes públicos baseada em relações da mais variada ordem, inclusive familiares. ${ }^{11}$ A relação entre Estado e empresas envolve, entre outros benefícios, a concessão de crédito subsidiado, bem como a participação acionária, tanto do próprio Estado como de fundos de pensão semipúblicos (NÖLKE, 2010, p. 7-8). Aliada à dispersão do capital geralmente verificada nas empresas familiares, essa atuação estatal nas áreas de investimento e crédito torna as empresas brasileiras menos suscetíveis às

\footnotetext{
${ }^{11}$ A pouca atenção dada às relações entre empresas e Estado na análise de Schneider (2009) acerca das HMEs é motivo de controvérsia não apenas em relação ao caso brasileiro, mas também no que se refere aos demais países da América Latina. Ver Sánchez-Ancochea (2009).
} 
flutuações do mercado financeiro (NÖLKE, 2010, p. 8). As relações entre capital e Estado parecem ainda substituir, em alguma medida, a coordenação das empresas entre si e com os sindicatos encontrados nos países de CME. As associações comerciais mostram-se, assim, fracas (NÖLKE, 2010 , p. 11), e sua relação com os sindicatos é, geralmente, mediada pelo Estado. (NÖLKE, 2010, p. 9)

\section{Capitalismo Hierárquico e Responsabilidade Social Empresa- rial}

Esta seção encerra o trabalho com uma análise da responsabilidade social empresarial em HMEs, com atenção especial para o caso brasileiro. Tendo em vista a escassez de dados disponíveis, entretanto, a parte subsequente do texto é primordialmente dedicada a levantar hipóteses aptas a orientar a pesquisa futura.

A relação entre variedades de capitalismo e responsabilidade social empresarial é examinada em trabalhos baseados na comparação originalmente feita por Hall e Soskice (2001) entre CMEs e LMEs. Tendo em vista o fato de as CMEs se caracterizarem por relações entre firmas e trabalhadores menos sujeitas às oscilações de mercado, bem como a inclinação paritária, com impacto até sobre a gestão das empresas, dessas relações, pode-se afirmar que a responsabilidade social empresarial é, ao menos no que se refere às condições de trabalho, um traço mais ou menos constante nas CMEs. Isso não significa, porém, que as LMEs sejam avessas à responsabilidade social, mas apenas que nelas falta certo arranjo institucional propício a essa responsabilidade. De fato, uma das conclusões de um trabalho pioneiro (MATTEN; MOON, 2008) acerca das repercussões de diferentes variedades de capitalismo para a responsabilidade social empresarial é que essa responsabilidade é mais explícita nas LMEs e mais implícita nas CMEs, isto é, que a responsabilidade como recurso discursivo (explícita) e ação espontânea se faz mais presente em países, como os EUA, em que a atenção das empresas aos interesses de outros atores, que não os acionistas, não seja uma direta imposição do arcabouço institucional (legal, inclusive) vigente. Chega-se a concluir, a esse respeito, que 
a responsabilidade social destina-se a suprir um défice de legitimidade de que soe padecer corporações atuantes em mercados menos regulados, razão pela qual se faria mais comum (de novo, como discurso e prática espontânea) em países de LME. (KINDERMANN, 2009; JACKSON; APOSTOLAKOU, 2010) $)^{12}$

Tendo em vista agora as particularidades de HMEs e as suas consequências para a responsabilidade social empresarial, pode-se propor uma primeira hipótese, elaborada à base da distinção entre HMEs e LMEs. Assim, admitindo-se que a responsabilidade social seja uma reação da empresa à necessidade de legitimar-se, e que essa necessidade decorra de uma percepção geral acerca das consequências funestas do mercado, pode-se esperar que o ímpeto para a responsabilidade seja reduzido em países, como os de HME, nos quais a importância das relações mediadas pelo mercado seja menor (hipótese n. 1).

Note-se que essa hipótese não apenas está de acordo com evidências de que práticas de responsabilidade social sejam mais comuns em países de LME (KINDERMANN, 2009; JACKSON; APOSTOLAKOU, 2010), mas também com a hipótese, mais geral, da influência de normas sociais sobre o comportamento empresarial (CAMPBELL, 2007, p. 958959), seja por razões estratégicas ou não. Há, no entanto, duas ressalvas a fazer. A primeira é a de que, se, por um lado, o défice de legitimidade das empresas e o chamamento à responsabilidade social são menores em mercados regulados, por outro não se pode se esquecer dos efeitos da regulação sobre essa responsabilidade. Em outras palavras, é bem possível que a falta de responsabilidade social "explícita" seja compensada, quem sabe até com sobra, pela responsabilidade social "implícita" decorrente das determinações legais, e isso ao menos, é claro, à medida que essas determinações se mostrem eficazes. A segunda ressalva é a de que a falta de regulação pode ser apenas um dos fatores a ensejar a disseminação, ou "institucionalização" (CAMPBELL, 2007, p. 959), do apelo à responsabilidade social empresarial. Outros desses fatores, como a desigualdade e o respeito aos direitos humanos, podem fazer com que as empresas se

\footnotetext{
12 Em sentido contrário, ver Gjølberg (2009), para quem as instituições características do welfare state influenciam positivamente a responsabilidade social além-fronteiras das firmas oriundas de países nos quais essas instituições se fazem presentes.
} 
submetam a exigências normativas independentemente da variedade de capitalismo (HME, LME, CME ou outra) em que atuem.

Feitas as ressalvas, considere-se, a fim de ilustrar a hipótese já enunciada, o caso das relações de trabalho. Diferentemente do que ocorre nas LMEs, essas relações podem se sujeitar, no caso das HMEs, a uma série de regras limitadoras da liberdade contratual, ainda que essas regras sejam resultado antes da intervenção estatal do que de acordos (característicos das CMEs) envolvendo firmas e sindicatos de trabalhadores. No entanto, ainda quando a legislação trabalhista seja, em grande medida, inobservada (algo atestado, nos países da América Latina, pelo alto percentual de trabalho informal), a sua vigência ajuda a conter o clamor público pelo trabalho decente. No caso brasileiro, em particular, em que a legislação trabalhista é acusada de inibir a oferta de emprego e de elevar o custo da atividade empresarial (o "custo Brasil"), o efeito da substituição do mercado pela intervenção estatal tem sido até mesmo o de ensejar apelos pela redução das obrigações das empresas para com os trabalhadores.

Uma segunda hipótese diz respeito agora à diferença entre HMEs e CMEs no que se refere à atuação das associações empresariais. Como visto, tanto as CMEs quanto as HMEs se caracterizam pela substituição parcial do mercado por outros meios de interação. A diferença entre as duas variedades de capitalismo, segundo propõe Schneider (2008), está no fato de esses meios serem eminentemente negociados (isto é, envolverem sujeitos em paridade de forças) nas CMEs e hierárquicos nas HMEs. Entre as interações habitualmente paritárias estão as promovidas pelas associações empresariais, as quais podem, pois, se mostrar cruciais para o desempenho das empresas em uma CME (tal como ocorre, por exemplo, na Alemanha), mas possuem um papel menos significativo nas HMEs (SCHNEIDER, 2008, p. 11-12). ${ }^{13}$ Pode-se postular, assim, que a responsabilidade social empresarial seja também dificultada, nas HMEs, pela falta de instâncias de deliberação coletiva das empresas entre si e com outros stakeholders, como trabalhadores, ONGs e mo-

\footnotetext{
13 Na América Latina, as relações entre firmas são ainda enfraquecidas pela atuação de multinacionais cujas principais instâncias decisórias se encontram além-fronteiras e pela dificuldade de interação entre os empresários locais e os representantes dessas multinacionais. (SCHNEIDER, 2009, p. 15)
} 
vimentos sociais (hipótese n. 2). A falta de relações significativas entre firmas pode ser considerada um empecilho à responsabilidade social, já que dificulta a autorregulação (CAMPBELL, 2007, p. 955-956), o aprendizado mútuo das empresas sobre os benefícios a longo prazo da responsabilidade social (CAMPBELL, 2007, p. 959) e o diálogo com outros grupos de stakeholders. (CAMPBELL, 2007, p. 960-962)

A exemplo da primeira, essa segunda hipótese se sujeita a ressalvas. Deve-se ponderar, assim, em primeiro lugar, que nada assegura que o estreitamento das relações entre firmas favoreça a responsabilidade social. Outro possível efeito desse estreitamento é exatamente o contrário, isto é, o de ensejar a ação coletiva das empresas para resistir à responsabilidade social (por exemplo, mediante lobby junto às autoridades). O que a hipótese recém-enunciada sugere, portanto, é tão-somente que as relações de cooperação duradoura baseadas em confiança mútua características das CMEs deixam aberta uma via de comunicação entre as empresas que facilita a autorregulação e o aprendizado. A fim de que essa via seja, de fato, empregada em benefício da responsabilidade social, é preciso que concorram outros fatores, estratégicos ou institucionais, tal como ocorre, por exemplo, em indústrias sob a ameaça de intervenção estatal ou cuja legitimidade seja especialmente contestada. O importante é salientar que, mesmo em circunstâncias nas quais esses outros fatores se façam presentes, uma resposta satisfatória das empresas pode ser impedida por problemas de ação coletiva e pela falta de canais estabelecidos de interação mediante os quais esses problemas sejam solucionados.

Outra observação se refere à deliberação envolvendo empresas e outros atores, como sindicatos e ONGs. Quanto a isso, deve-se considerar que a falta de um diálogo capaz de levar, senão à coincidência, ao menos a uma aproximação das convicções de diferentes partes pode ser atribuída, nas HMEs, tanto à insignificância das associações empresariais como à intervenção do Estado, que torna dispensável não apenas a obtenção do consenso, mas até a negociação entre grupos com interesses antagônicos. Que uma atuação significativa das associações empresariais não acarrete necessariamente um incremento do diálogo entre as empresas e outros grupos de stakeholders é atestado pelo caso brasileiro, no qual um empre- 
sariado tradicionalmente tido como pouco apto à ação coletiva tem conseguido, a partir da década de 1990, valer-se da Confederação Nacional da Indústria (CNI) para a defesa dos seus interesses. Ao invés, no entanto, da negociação com outros atores de importância vital para a indústria, como bancos e trabalhadores, a principal estratégia da CNI vem sendo a de procurar influenciar as ações de governo em favor de medidas para a redução do custo da atividade industrial (o "custo Brasil"), bem como nas tratativas para a criação da Área de Livre Comércio das Américas, a Alca. (MANCUSO; OLIVEIRA, 2006; MANCUSO, 2004)

Uma terceira hipótese tem a ver com relações de hierarquia estabelecidas entre empresas ao longo da cadeia de produção, isto é, entre empresas e seus fornecedores ou clientes. Uma razão para que em HMEs essas relações sejam mais duradouras do que em LMEs, mas menos negociadas do que em CMEs, é a formação de oligopólios, favorecida, no caso da América Latina, pela atuação das multinacionais e dos conglomerados empresariais locais (SCHNEIDER, 2009, p. 8). Com base nisso, é de imaginar que práticas de responsabilidade social sejam mais facilmente impostas pelas empresas aos seus fornecedores e clientes nas HMEs (hipótese n. 3). Análoga a essa é uma hipótese que diz respeito às relações da firma com seus trabalhadores, que também se mostram hierárquicas devido à frouxidão ou ineficácia da legislação trabalhista e à fraca atuação dos sindicatos. ${ }^{14} \mathbf{A}$ hierarquização das relações de trabalho facilita a adesão dos trabalhadores a medidas de responsabilidade social decretadas pelos gestores da empresa (hipótese n. 4).

Uma ressalva óbvia é a de que as hipóteses em questão não insinuam que as relações hierárquicas das firmas entre si e entre as firmas e seus empregados resultarão obrigatoriamente em incremento da responsabilidade social, mas apenas que, uma vez motivadas a promover a atuação socialmente responsável sua e de suas parceiras (motivação essa a depender de outros fatores), empresas participantes de relações hierárquicas possuem maior chance de êxito.

\footnotetext{
14 Na América Latina, contribui para a hierarquização das relações de trabalho o predomínio do trabalho de baixa sofisticação (SCHNEIDER, 2009, p. 12-13), que torna o trabalhador mais facilmente substituível.
} 
Outra ressalva decorre da dúvida sobre a eficácia das sanções como meio para incitar à obediência. Implícita, na hipótese de que a hierarquização das relações com parceiros e empregados colabore para a eficácia das medidas de responsabilidade social que uma empresa queira impor, está a ideia de que a atividade sancionadora, que graças ao seu poderio as grandes corporações estão aptas a exercer, seja um fator determinante da obediência aos ditames estabelecidos por essas corporações. Tendo em vista as evidências de inúmeros estudos comportamentais, no entanto, afirma-se que a estratégia mais promissora para obter o respeito às normas legais e às diretrizes de uma organização não é a de "comando-e-controle", baseada na aplicação de sanções, mas a "autorregulatória", cujo objetivo é a "ativação de juízos éticos" capaz de fazer com que trabalhadores ${ }^{15}$ sejam intrinsicamente motivados (isto é, motivados pelo seu próprio desejo, e não pela ameaça de sanção ou promessa de recompensa) a se conduzir conforme as regras da organização (TYLER, 2005). ${ }^{16}$ Embora a superioridade da autorregulação sobre o controle externo não signifique negar certa efícácia a este último, o argumento leva a cogitar se as relações dialogadas características das CMEs não acabariam levando vantagem no que refere à disseminação das políticas de responsabilidade social de uma empresa entre seus empregados, fornecedores e clientes. Tal cogitação ganha força quando adicionada à hipótese de que a motivação intrínseca para a obediência não esteja relacionada apenas à moralidade da norma legal ou à diretriz organizacional que se queira obedecida, mas também à sua legitimidade, a qual seria uma função, entre outros fatores, do modo como as decisões da firma são tomadas. (TYLER, 2005, p. 1.310)

No que se refere aos investidores externos, a hierarquização da gestão da firma pode decorrer tanto da capacidade de autofinanciamento quanto da concentração do investimento externo e da dependência da

\footnotetext{
15 A análise de Tyler se refere ao comportamento de empregados, mas pode ser estendida a outros atores sujeitos às determinações dos dirigentes de uma organização, como é o caso de fornecedores e clientes.

16 As sanções e outros estímulos externos também podem ter o efeito funesto de solapar a motivação intrínseca a atuar da maneira prescrita. Sobre isso, ver, Deci, Koestner e Ryan (1999); Shinada e Yamagishi (2008, p. 112-113); Gneezy, Meier e Rey-Biel (2011).
} 
firma em relação ao investidor. Em qualquer dos casos, substitui-se o investimento por meio de mercado acionário, característico das LMEs, e a cooperação mais estável, baseada em um robusto fluxo de informações, verificada nas CMEs. Assim, considerando-se a influência dos investidores externos sobre o comportamento empresarial, pode-se então supor que a responsabilidade social empresarial nas HMEs ou se mantém alheia às demandas de investidores (nos casos de autofinanciamento) ou é fortemente determinada por essas demandas (nos casos de hierarquização da relação entre firma e investidor) (hipótese n. 5).

De acordo com Schneider (2009, p. 14), o poderio dos grupos de empresas locais na América Latina facilita o autofinanciamento. Mesmo quando ofertam ações em bolsa, é comum que parte substantiva do capital se mantenha nas mãos dos gestores e de seus familiares, o que, além de desestimular a participação de investidores minoritários, acaba reduzindo a dependência em relação ao mercado acionário. (SCHNEIDER, 2009, p. 14)

Em casos como o brasileiro, nos quais os bancos, inclusive públicos, são uma fonte importante de financiamento (NÖLKE, 2010, p. 8), o que pode se verificar é uma estreita dependência da firma em relação ao investidor externo, principalmente quando se trate de crédito público subsidiado. Em tais circunstâncias, a responsabilidade social é uma possível decorrência das exigências do Estado-investidor, a depender, é claro, das políticas estatais quanto à responsabilidade empresarial e da capacidade das autoridades para monitorar o comportamento das empresas. ${ }^{17}$

Por fim, a hierarquização também pode ter impacto sobre as atividades de responsabilidade social que a empresa exerça a fim de atender às preferências de certos grupos de stakeholders, em especial trabalhadores e consumidores. Contribui para que as relações das empresas com esses grupos se hierarquizem a fragilidade das associações (sindicatos, associações de consumidores, ONGs) por um lado e, por outro, a formação de oligopólios. Essa hierarquização corresponde a uma redução da in-

\footnotetext{
17 Caso exemplar é o do Protocolo Verde, carta de intenções firmada em 1995 por bancos públicos brasileiros que prevê a inclusão da proteção ao meio ambiente entre os critérios para concessão de crédito. Em 2009, a Federação Brasileira de Bancos, FEBRABAN, aderiu ao Protocolo.
} 
fluência direta de stakeholders sobre o comportamento empresarial, além de impedir que a preferência por empresas socialmente responsáveis se traduza em decisões de mercado, como a da compra de um produto ou a da procura pelo emprego (hipótese n. 6).

Uma ressalva a respeito dessa última hipótese diz respeito às multinacionais, cujo comportamento em HMEs pode sujeitar-se à influência de atores estrangeiros. Assim, mesmo que a hierarquização as torne infensas para as demandas de grupos locais, outras relações, não hierárquicas, que essas corporações possuam além-fronteiras podem forçar uma atuação socialmente responsável. Observação análoga vale para firmas dos países de HME com atividade em outros países, como as multinacionais com origem na América Latina ("multilatinas") e empresas exportadoras.

\section{Conclusões}

A análise feita na seção precedente teve, sobretudo em vista, as consequências para a responsabilidade social empresarial da variedade hierárquica de capitalismo, a $\mathrm{HME}$. As conclusões tiradas são de interesse para a responsabilidade social empresarial no Brasil, portanto, apenas à medida que sejam encontradas no capitalismo brasileiro as características da variedade em questão, algo que chama a atenção para a importância de estudos que, dando sequência a trabalhos pioneiros como os de Schneider (2009) e Nölke (2010), contribuam para a descrição das particularidades institucionais do capitalismo no Brasil.

Outra lacuna evidente é a que se refere à confirmação das hipóteses apresentadas. Como essas hipóteses se baseiam no pressuposto de que a responsabilidade social seja influenciada pelas características institucionais de cada país, seria útil comparar o comportamento das empresas no Brasil com o que se verifica em outros lugares e, em particular, em países com uma variante de capitalismo marcadamente distinta. O presente artigo convida, assim, à realização de pesquisa empírica destinada a conhecer os fatores, estratégicos e institucionais, que levam as empresas no Brasil a se conduzir de maneira socialmente responsável e a comparar as práticas 
empresariais de responsabilidade social verificadas no Brasil e em países de LME e CME.

O trabalho iniciou dando ênfase à relação entre a responsabilidade social empresarial e o Direito, e encerra, agora, com algumas breves considerações sobre a importância de suas conclusões para as políticas públicas de regulação empresarial. Um desafio para o qual o presente estudo ajuda a chamar a atenção é o de determinar táticas eficazes de regulação para empresas em países cujos traços institucionais se aproximem aos de uma HME. Duas estratégias podem, a esse respeito, ser cogitadas. A primeira delas consistiria em lançar mão de medidas que procurem tirar proveito das potencialidades das HMEs para a responsabilidade social, sem descurar, ao mesmo tempo, dos limites que essa variedade de capitalismo impõe a essa responsabilidade. Por exemplo, se uma das razões da hierarquização das relações da firma é a falta de relações negociadas, não mediadas pelo Estado, entre o empresariado, de um lado, e trabalhadores, ONGs e outros stakeholders de outro, a solução, a seguir essa primeira estratégia, seria admitir de antemão a pouca probabilidade de sucesso de táticas de regulação descentralizada e buscar ampliar a intervenção estatal sobre a atividade empresarial, tratando, assim, de assegurar a responsabilidade social por meio dessa intervenção. Uma segunda estratégia, em contrapartida, seria a de conceber políticas públicas destinadas à reforma do capitalismo vigente, isto é, políticas mediante as quais se tentassem promover em países de capitalismo predominantemente hierárquico alterações institucionais ${ }^{18}$ que aproximem esses países, ao menos naquilo capaz de ensejar a responsabilidade social empresarial, de outras variedades de capitalismo. Retomando o exemplo, essa estratégia poderia se traduzir então em medidas que atribuíssem competência regulatória a sindicatos, ONGs e movimentos sociais, de maneira a aumentar a capacidade de barganha desses atores em face das empresas e a encorajar, assim, o surgimento de relações negociadas envolvendo empresários e outros stakeholders.

18 Para uma aplicação da abordagem das variedades de capitalismo ao tema da mudança institucional, ver Hall e Thelen (2009). 


\section{Referências}

AGUILERA, Ruth V.; RUPP, Deborah E.; WILLIAMS, Cynthia A. Putting the s back in corporate social responsibility: a multilevel theory of social change in organizations. Academy of Management Review, Nova York (EUA), v. 32, n. 3, p. 836-863, 2007.

AMAESHI, Kenneth; AMAO, Olufemi O. Corporate social responsibility in transnational spaces: exploring influences of varieties of capitalism on expressions of corporate codes of conduct in Nigeria. Journal of Business Ethics, Brandon (Canadá), v. 86, p. 225-239, 2009.

BALESTRO, Moisés Vilamil; MARINHO, Danilo Nolasco Cortes; WALTER, Maria Inez Machado Telles. Seguro-desemprego no Brasil: a possibilidade de combinar proteção social e melhor funcionamento do mercado. Revista Sociedade e Estado, Brasília, v. 26, n. 2, p. 185-208, maio-ago. 2001.

BILCHITZ, David. O marco Ruggie: uma proposta adequada para as obrigações de direitos humanos das empresas? Sur, São Paulo, v. 7, n. 12, p. 209-241, jun. 2010.

BRESSER-PEREIRA, Luiz Carlos. Five models of capitalism. Brazilian Journal of Political Economy, São Paulo, v. 32, n. 1(126), p. 21-32, jan.-mar. 2012.

CAMPBELL, John L. Institutional analysis and the paradox of corporate social responsibility. American Behavioral Scientist, Sedona (EUA), v. 49, p. 925-938, 2006.

.Why would corporations behave in socially responsible ways?

An institutional theory of corporate social responsibility. Academy of Management Review, Nova York (EUA), v. 32, n. 3, p. 946-967, 2007.

COLQUITT, Jason A.; CONLON, Donald E.; WESSON, Michael J. Justice at the millennium: a meta-analytica review of 25 years of organizational justice research. Journal of Applied Psychology, Melbourne (Austrália), v. 86, n. 3, p. 425-445, 2001. 
DECI, Edward L.; KOESTNER, Richard; RYAN, Richard M. A metaanalytic review of experiments examining the effects of extrinsic rewards on intrinsic motivation. Psychological Bulletin, Berkeley (EUA), v. 125, n. 6, p. 627-668, 1999.

DELGADO, Ignacio Godinho; CONDÉ, Eduardo Salomão; ÉSTHER, Angelo Brigato. Cenários da diversidade: variedades de capitalismo e política industrial nos EUA, Alemanha, Espanha, Coreia, Argentina, México e Brasil (1998-2008). DADOS - Revista de Ciências Sociais, Rio de Janeiro, v. 53, n. 4, p. 959-1.008, 2010.

DiMAGGIO, Paul J.; POWELL, Walter W. The iron cage revisited: institutional isomorphism and collective rationality in organizational fields. American Sociological Review, Nashville (EUA), v. 48, n. 2, p. 147-160, abr. 1983.

DU, Shuili; BATTACHARYA, C. B.; SEN, Sankar. Reaping relational rewards from corporate social responsibility: the role of competitive positioning. International Journal of Research in Marketing, Herzliya (Israel), v. 24, p. 224-241, 2007.

EDELMAN, Lauren B.; UGGEN, Christopher; ERLANGER, Howard $\mathrm{S}$. The endogeneity of legal regulation: grievance procedures as rational myth. American Journal of Sociology, Chicago (EUA), v. 105, n. 2, p. 406-454, set. 1999.

GARRIGA, Elisabet; MELÉ, Domènec. Corporate social responsibility theories: mapping the territory. Journal of Business Ethics, Brandon (Canadá), v. 53, p. 51-71, 2004.

GJØLBERG, Maria. The origin of corporate social responsibility: global forces or national legacies? Socio-Economic Review, Oxford (Inglaterra), v. 7, p. 605-637, 2009.

GNEEZY, Uri; MEIER, Stephan; REY-BIEL, Pedro. When and why incentives (don't) work to modify behavior. Journal of Economic Perspectives, Pittsburgh (EUA), v. 5, n. 4, p. 1-21, 2011. 
GRAVES, Samuel B.; WADDOCK, Sandra A. Waddock. Institutional owners and social performance. Academy of Management Review, Nova York (EUA), v. 37, n. 4, p. 1.034-1.046, 1994.

GREENING, Daniel W.; TURBAN, Daniel B. Corporate social responsibility as a competitive advantage in attracting a quality workforce. Business \& Society, Chicago (EUA), v. 39, n. 3, p. 254-280, set. 2000 .

GUNNINGHAM, Neil; REES, Joseph. Industry self-regulation: an institutional perspective. Law \& Policy, Denver (EUA), v. 19, n. 4, p. 363-414, out. 1997.

HALL, Peter A.; SOSKICE, David. An introduction to varieties of capitalism. In: HALL, Peter A.; SOSKICE, David (Org.). Varieties of capitalism: The Institutional Foundations of Comparative Advantage. Nova York: Oxford University Press, 2001. (p. 1-68)

HALL, Peter A.; TELLEN, Kathleen. Institutional change in varieties of capitalism. Socio-Economic Review, Oxford (Inglaterra), v. 7, p. 7-34, 2009.

JACKSON, Gregory; APOSTOLAKOU, Androniki. Corporate social responsibility in Western Europe: an institutional mirror or substitute? Journal of Business Ethics, Brandon (Canadá), v. 94, p. 371-394, 2010.

JOHNSON, Richard A.; GREENING, Daniel. W. The effects of corporate governance and institutional ownership types on corporate social performance. Academy of Management Review, Nova York (EUA), v. 42, n. 5, p. 564-576, 1999.

KINDERMANN, Daniel. Why do some countries get CST sooner, and in greater quantity, than others? The political economy of corporate responsibility and the rise of market liberalism across the OECD: 19772007. [2009]. WZB Discussion Paper. Disponível em: $<$ http://ideas.repec. org/p/zbw/wzbkpw/spiii2009301.html>. Acesso em: 8 jun. 2012.

LOBEL, Orly. The renew deal: the fall of regulation and the rise of governance in contemporary legal thought. University of Minnesota Law Review, Minnesota (EUA), v. 89, p. 342-470, 2004. 
MANCUSO, Wagner Pralon. O empresariado como ator político no Brasil: balanço da literatura e agenda de pesquisa. Revista de Sociologia e Política, Curitiba, n. 28, p. 267-271, jun. 2007.

MANCUSO, Wagner Pralon; OLIVEIRA, Amâncio Jorge de. Abertura econômica, empresariado e política: os planos doméstico e internacional. Lua Nova, São Paulo, v. 69, p. 147-172, 2006.

MATTEN, Dirk; MOON, Jeremy. "Implicit" and "explicit" CSR: a conceptual framework for a comparative understanding of corporate social responsibility. Academy of Management Review, Nova York (EUA), v. 33, p. 404-424, 2008.

MEYER, John W.; ROWAN, Brian. Institutionalized organizations: formal structure as myth and ceremony. American Journal of Sociology, Chicago (EUA), v. 83, n. 2, p. 340-363, set. 1977.

MOHR, Louis A.; WEBB, Deborah J. The effects of corporate social responsibility and price on consumer responses. The Journal of Consumer Affairs, Ithaca (EUA), v. 39, n. 1, p. 121-147, 2005.

NÖLKE, Andreas. A “BRIC” variety of capitalism and social inequality: the case of Brazil. Revista de Estudos e Pesquisas sobre as Américas, Brasília, v. 4, n. 1, p. 1-14, 2010.

ORLITZKY, Marc; SCHMIDT, Frank L.; RYNES, Sara L. Corporate social and financial performance: a meta-analysis. Organization Studies, Lyon (França), v. 24, n. 3, p. 403-441, 2003.

O'ROURKE, Anastasia. A new politics of engagement: shareholder activism for corporate social responsibility. Business Strategy and the Environment, Klong Luang (Tailândia), v. 12, n. 4, p. 227-239, 2003.

OSTROM, Elinor. Collective action and the evolution of social norms. Journal of Economic Perspectives, Pittsburgh (EUA), v. 14, n. 3, p. 137-158, 2000.

OSTROM, Elinor; WALKER, James; GARDNER, Roy. Covenants with and without a sword: self-governance is possible. The American Political cience Review, Washington, D. C. (EUA), v. 86, n. 2, p. 404417, jun. 1992. 
SÁNCHEZ-ANCOCHEA, Diego. State, firms, and the process of industrial upgrading: Latin America's variety of capitalism and the Costa Rican experience. Economy and Society, Londres (Inglaterra), v. 38, n. 1, p. 62-86, fev. 2009.

SCHNEIDER, Ben Ross. Hierarchical market economies and varieties of capitalism in Latin America. Journal of Latin American Studies, Cambridge (Inglaterra), v. 41, n. 3, p. 553-575, 2009.

SCHNEIDER, Ben Ross. Comparing capitalisms: liberal, coordinated, network, and hierarchical varieties. 2008. Disponível em: $<$ http://www. ces.fas.harvard.edu/events/papers/Schneider_Comparing_Capitalisms. pdf $>$. Acesso em: 20 jun. 2012.

SCHNEIDER, Ben Ross; KARCHER, Sebastian. Complementarities and continuities in the political economy of labour markets in Latin America. Socio-Economic Review, Oxford (Inglaterra), v. 8, p. 623-651, 2010.

SCOTT, W. Richard. Approaching adulthood: the maturing of institutional theory. Theory and Society, Nova York (EUA), v. 37, p. 427-442, 2008.

SHINADA, Mizuho; YAMAGISHI, Toshio. 2008. Bringing back Leviathan into social dilemmas. In: BIEL, A. et al. (Org.). New issues and paradigms in research on social dilemmas. Nova York: Springer, 2008, p. 93-123.

SUCHMAN, Mark E. Managing legitimacy: strategic and institutional approaches. Academy of Management Review, Nova York (EUA), v. 20, n. 3, p. 571-610, 1995.

SUNSTEIN, Cass R. On the expressive function of law. University of Pennsylvania Law Review, Pennsylvania (EUA), v. 144, p. 2.021-2.053, 1996.

TRUBEK, David M.; TRUBEK, Louise G. New governance and legal regulation: complementarity, rivalry, and transformation. Columbia Journal of European Law, Columbia (EUA), v. 13, p. 539-564, 2006. 
TYLER, Tom R. Promoting employee policy adherence and rule following in work settings: the value of self-regulatory approaches.

Brooklyn Law Review, Nova York (EUA), v. 70, n. 4, p. 1.287-1.312, 2005.

. Procedural fairness and compliance with the law. Swiss Journal of Economics and Statistics, Zurique (Suíça), v. 133, n. 2/2, p. 219-240, 1997.

WADDOCK, Sandra A.; GRAVES, Samuel B. The corporate social performance-financial performance link. Strategic Management Journal, Chicago (EUA), v. 18, n. 4, p. 303-319, 1997.

Leandro Zanitelli é Doutor em Direito pela Universidade Federal do Rio Grande do Sul (UFRGS), com estágio de Pós-Doutorado na Universidade de Hamburgo, Alemanha. É Professor do Curso de Graduação em Direito do Centro Universitário Ritter dos Reis (UniRitter) e Professor e Coordenador do Programa de Pós-Graduação Stricto Sensu - Mestrado Acadêmico em Direito do UniRitter. E-mail: leandrozanitelli@gmail.com.

Endereço profissional: Centro Universitário Ritter dos Reis. Departamento de Direito. Rua Orfanotrófio, 555, CEP:

90.840-440. Alto Teresópolis, Porto Alegre/RS. 